\title{
Involuntary sterilisation of HIV-positive women in South Africa: A current legal perspective
}

\author{
M du Toit, LLB (Rhodes), LLM (Stellenbosch) \\ Atlantic Fellow for Health Equity in South Africa based at Tekano Atlantic Fellows, Cape Town, South Africa
}

Corresponding author: M du Toit (m.dutoit@atlanticfellows.org)

This article examines the reality of HIV-positive women being subjected to perpetual stigmatisation as a result of involuntary sterilisation practices. The reproductive autonomy and dignity of HIV-positive persons is protected by various constitutional provisions, and a legal framework providing for the requirement of informed consent, as well as the prohibition of discrimination on the grounds of HIV status. This article considers the issues of both informed consent and discrimination in the context of the practice of involuntary sterilisation of HIVpositive women. The article considers the legal framework in light of the physical, emotional, social and cultural implications for HIV-positive women who are subjected to involuntary sterilisation.

S Afr J Bioethics Law 2018;11(2):80-84. DOI:10.7196/SAJBL.2018.v11i2.641

The involuntary sterilisation of HIV-positive women in South Africa (SA) is not a fiction found in medical horror stories, but a tragic reality of perpetual stigmatisation of the most vulnerable in society. Involuntary sterilisation is imposed on HIV-positive women to prevent mother-to-child transmission (MTCT) of HIV. There is both a lack of information on this violation, and a lack of recourse for its victims. First-hand accounts provide evidence that this is a fearful reality which HIV-positive women are exposed to in exercising their reproductive health rights. ${ }^{[1]}$ Involuntary sterilisation has grave consequences for women physically, emotionally, socially and culturally. It also violates women's enjoyment of their reproductive health rights, as McLaughlin ${ }^{[2]}$ notes:

'Sterilisation procedures should be voluntary medical surgeries due to the general irreversible nature of sterilisation, which leaves a lasting change on one's bodily functions and capabilities to exercise one's right to reproduce.'

This argument emphasises the reasons that sterilisation is a procedure that requires informed consent. HIV-positive women who are involuntarily sterilised are subjected to a usually permanent change in their body, and subsequently, their reproductive health rights. Involuntary sterilisation is inherently discriminatory, as the motivating reason behind this practice is'to deny specific populations the ability to procreate due to a perception that they are less than ideal members of society. ${ }^{[[3]}$ If this occurs based on a woman's HIV status, it further amounts to discrimination. The crux of the problem with this practice is therefore informed consent, and discrimination on the grounds of HIV status.

This article seeks to examine this practice from an SA legal perspective. Firstly, the issue will be contextualised to explain why it happens, and the effects thereof. The constitutional and legal framework will then be examined to understand which rights and laws are implicated under SA law. The two focal issues, informed consent and discrimination, will then be examined in light of the legal framework and context provided. This article seeks to examine the issues from a legal perspective and consider possible ways forward.

\section{Placing the issue in context}

HIV-positive women are being involuntarily sterilised to limit the transmission of HIV from mother to child. ${ }^{[4]}$ The rationale behind this practice provided by healthcare workers is four-fold. ${ }^{[5]}$ Firstly, the HIV status and socioeconomic circumstances of the women are deemed to influence the healthcare workers as to the women's suitability to bear more children. ${ }^{[5]}$ Secondly, healthcare workers see sterilisation as a means to prevent children being born HIV-positive. ${ }^{[5]}$ Thirdly, owing to the influence that HIV can have on a person's life expectancy, some healthcare workers believe that this practice avoids children being left motherless or orphaned..$^{[5]}$ Lastly, it is argued that HIV-positive women should not expose themselves to harm by carrying a child. ${ }^{[5]}$

These rationales are based on misconceptions. They do not give due credit to the effectiveness of antiretrovirals and medicine in preventing MTCT of HIV. ${ }^{[5]}$ These reasons reflect the social context facing HIV-positive women wishing to exercise their reproductive health rights. The social conception of HIV transmission creates a bias against women, as our patriarchal society sees the man as the victim of women's promiscuity. ${ }^{[4]}$ Those living with HIV are viewed as having fault in some way, and the fear, ignorance and denial accompanying the prevalence of HIV only adds to the stigmatisation of HIV-positive persons. ${ }^{[4]}$ This leaves HIV-positive persons, especially women, especially vulnerable.

Adding to the vulnerability and stigmatisation imposed by their HIV-status, women are also subjected to stigma regarding their fertility. Generally, and especially in Africa, a woman's ability to bear children is perceived to be her 'role, purpose and identity!'[4] Consequently, the inability to bear children is seen as a failure of social expectations, and has actually been described as 'the greatest 
calamity that can befall any society.[4] Various SA cultural values place importance on children and family. ${ }^{[4]} \mathrm{A}$ study ${ }^{[6]}$ on the reproductive intentions of HIV-positive persons noted: ${ }^{[6]}$

'Cultural values placed on women's fertility assign significant social status to women who bear children, and childlessness often carries negative social consequences.'

The social, cultural and gendered pressure on women to bear children inevitably implicates their self-worth and dignity. ${ }^{[7]} \mathrm{A}$ lack of children or inability to bear children further stigmatises women. ${ }^{[4]}$ It is thus that HIV-positive women who are sterilised face a double-edged sword of stigmatisation. A vicious cycle of stigmatisation is created wherein HIV-positive women are subjected to prejudicial treatment from healthcare workers, which sometimes results in the involuntary sterilisation of women, and then, women face further social and cultural vulnerability as a result of their inability to bear children. This necessarily implicates the rights of these women. The constitutional and legal framework will now be considered in light of this context.

\section{Constitutional and legal framework}

Section 27(1) of the Constitution of the Republic of SA, 1996 provides everyone with the right of access to healthcare, including reproductive healthcare. Section 12 of the Constitution provides rights regarding the freedom and security of the person. Section 12(2) states:

'Everyone has the right to bodily and psychological integrity, which includes the right:

(a) to make decisions concerning reproduction;

(b) to security in and control over their body; and

(c) not to be subjected to medical or scientific experiments without their informed consent.

Section 12 is fundamental to the issue of involuntary sterilisation, as it recognises both reproductive health rights and informed consent.

Section 9 of the Constitution provides for the right to equality, and lists grounds upon which people may not be discriminated against. HIV is not a listed ground under section 9, but has been recognised by the SA Constitutional Court as an analogous ground, as will be examined below. As such, HIV-positive women's reproductive autonomy is protected by various constitutional provisions.

Furthermore, legislation has been enacted to give effect to section 9 of the Constitution: the Promotion of Equality and Prevention of Unfair Discrimination Act No. 4 of 2000 (PEPUDA). PEPUDA recognises that discrimination can be systemic in nature, and that there is a need to address the patriarchal society prevalent in SA - both these aspects of discrimination are relevant to the examination of the issue of involuntary sterilisation. The preamble of PEPUDA states:

'The consolidation of democracy in our country requires the eradication of social and economic inequalities, especially those that are systemic in nature, which were generated in our history by colonialism, apartheid and patriarchy, and which brought pain and suffering to the great majority of our people.'

PEPUDA places an emphasis on consent in healthcare services in its Illustrative List of Unfair Practices in Certain Sectors. In holding that neither the state nor individuals may unfairly discriminate against any person, PEPUDA defines discrimination as: 'any act or omission, including a policy, law, rule, practice, condition or situation which directly or indirectly:

(a) imposes burdens, obligations or disadvantages on; or

(b) withholds benefits, opportunities or advantages from, any person on one or more of the prohibited grounds.'

Other legislation also contributes to the framework. Section 6 of the National Health Act No. 61 of 2003 (NHA) provides that the patient must have full knowledge of their health status, all the possible diagnostic procedures, the risks and benefits of each and the right to refuse treatment. Section 7 of the NHA further provides the requirement that patients must consent to treatment, and that healthcare workers must take steps to obtain informed consent from the patient.

The Sterilisation Act No. 44 of 1998 recognises the constitutional rights referred to above. The Sterilisation Act deals with instances where consent cannot be obtained owing to the impaired capacity of the patient, and other regulations regarding sterilisation procedures. Section 4 elaborates on the requirement for consent:

"'[C]onsent" means consent given freely and voluntarily without any inducement and may only be given if the person giving it has

(a) been given a clear explanation and adequate description of the (i) proposed plan of the procedure; and

(ii) consequences, risks and the reversible or irreversible nature of the sterilisation procedure;

(b) been given advice that the consent may be withdrawn any time before the treatment; and

(c) signed the prescribed consent form.'

In addition to involuntary sterilisation violating health rights, the right to freedom and security of the person and the right to equality and non-discrimination, it also impedes on the right to information, under section 32 of the Constitution. The right to access to information includes the right to any information necessary to protect your rights, such as reproductive health rights.

This illustrates the nature of SA's constitutional rights related to informed consent. However, there is a great disparity between this detailed understanding of consent and the circumstances under which it must be obtained (that of an informed patient), and the practical execution of obtaining consent for sterilisation, especially in cases of HIV-positive women. The examination now turns to the issue of consent, as informed by the legal framework and context.

\section{The issue of consent}

While there have been official reports of women in SA being involuntarily sterilised, there has not yet been a case on this issue. As such, there is a need to rely on neighbouring jurisprudence. It is justifiable to do so, as the circumstances and issues of the case are similar to the issues faced in the SA context, and can therefore provide an illustrative example of jurisprudence on this issue.

The Namibian case of LM $\vee$ Government of the Republic of Namibia ${ }^{[8]}$ focused on the issue of coerced sterilisation and discrimination on the grounds of HIV status. Regarding coercion, the issue of consent was raised by the facts. Three women, all HIV-positive and pregnant, were already in labour when 'consent' was obtained. LM had been in labour for over 14 hours when she was given the 
consent form to sign on a stretcher outside the theatre (prior to a caesarean section). Similarly, MI had been in labour for hours when she, according to her testimony, was told, not asked, to sign the consent form. In all three circumstances, there was no evidence to suggest that the women had been properly informed.

SA law on informed consent is based on the doctrine of volenti non fit injuria ('to a willing person, injury is not done'). ${ }^{[9]}$ The legal requirements are contained in the NHA, as examined above. In case law, the locus classicus is Castell $v$ De Greef, ${ }^{[10]}$ where an operation performed by a plastic surgeon on the plaintiff's breasts resulted in complications that the patient had not been informed of prior to surgery. Furthermore, the patient argued that she would not have consented to the procedure had she been aware of this risk. Justice Ackermann laid out the requirements for informed consent as follows (paragraph 80): ${ }^{[10]}$

(a) The consenting party 'must have had knowledge and been aware of the nature and extent of the harm or risk';

(b) The consenting party 'must have appreciated and understood the nature and extent of the risk';

(c) The consenting party 'must have consented to the harm or assumed the risk';

(d) The consent 'must be comprehensive, that is extend to the entire transaction, inclusive of its consequences'

While the present article is not concerned with risk, but rather with the direct result of a medical procedure (sterilisation), the last requirement is of particular relevance. This requirement indicates that a patient must be aware of and appreciate the nature and extent of the procedure, and must consent to the consequences. Involuntary sterilisation, or sterilisation performed under the pseudo-consent illustrated by LM, does not meet this requirement. Informed consent, as provided for in the Constitution, legislation and the common law, is, as put by Barit: ${ }^{[9]}$

'part of the shift in medicine from a paternalistic environment to one in which patients have control over their own bodies and the right to make decisions about what happens to it.'

Informed consent is fundamental to a person's reproductive autonomy. ${ }^{[11]}$ This autonomy exists even when others disagree with the individual's choices, and it is explicitly protected in law. ${ }^{[1]]}$

The World Health Organization has elaborated on the information required for informed consent regarding sterilisation procedures. ${ }^{[12]}$ The patient must know that sterilisation is a surgical procedure with both risks and benefits. The patient must be informed of whether or not the procedure is permanent, and the likelihood of future pregnancies. The patient must understand that refusing to undergo the sterilisation procedure will not be to the detriment of their health. The patient must also be informed of other forms of contraception or sterilisation available. In light of this understanding, a patient cannot be denied other healthcare treatment if she refuses to consent to sterilisation, nor can a patient be threatened that she will not receive certain care if she does not consent. ${ }^{[12]}$ First-hand accounts indicate that some women are in fact told that they will not receive maternal care or HIV treatment if they do not consent to sterilisation..$^{[1]}$

Obtaining consent is influenced by the power imbalance which exists between the patient and the healthcare worker, and this power imbalance may further be gendered. As observed by Mamad, such power imbalances may result in the patient's choices 'being determined by the health workers' perceptions, preferences and values, consciously or unconsciously. ${ }^{\prime[4]}$ The International Community of Women comments on the effect of this power imbalance: ${ }^{[7]}$

'Gender inequalities and unequal power dynamics inherent within societies around the world - and particularly in the provision of healthcare services - make it challenging for women to assert their reproductive rights, and ultimately, to have their autonomy and decision-making respected.'

As explained above, HIV-positive women are stigmatised and this social discernment inevitably influences the healthcare workers' perception, which is then directly or indirectly imposed on the patient. The information provided to a patient on which informed consent is to be based can also be influenced by the healthcare workers' perceptions.

Badul and Strode ${ }^{[5]}$ see consent as a process, and not an outcome. There must be an engagement between the patient and the doctor that is informative, and not subject to prejudicial influences. The mere signing of a form does not amount to consent, as was highlighted in the LM case. Obtaining consent is not merely a procedural anomaly that can be imposed on a patient at a healthcare worker's discretion. It is subsequently necessary to consider whether healthcare workers impose their perceptions on these women because of their HIV status, and if so, whether this amounts to discrimination (although it may be argued that involuntary sterilisation is inherently discriminatory, as noted above).

\section{The issue of discrimination}

Section 9 of the Constitution protects against unfair discrimination. The test for determining whether law or conduct amounts to unfair discrimination was developed in Harksen v Lane. ${ }^{[13]}$ The test is twofold. Firstly, it must be determined whether the law or conduct at issue differentiates between persons (paragraph 53). ${ }^{[13]}$ In the affirmative, it must be determined if the differentiation bears a rational connection to a legitimate government purpose. The second leg of the test considers whether the differentiation amounts to discrimination, and then whether the discrimination is fair. If the differentiation is on a ground listed in section 9 of the Constitution, then it amounts to discrimination. If it is not on a listed ground, then it will depend on the differentiation's potential to impair the human dignity of persons. Discrimination is presumed to be unfair if it is on a listed ground under section 9 of the Constitution. To determine unfairness on nonlisted grounds, the impact of the discrimination is considered.

HIV status is not a listed ground. However, the Constitutional Court has held that it amounts to an analogous ground, as discrimination on the basis of a person's HIV status impacts negatively on a person's dignity and it is based on an 'ill-informed prejudice.[14] Discrimination based on a person's HIV status was the issue in Hoffman v SAA. ${ }^{[14]}$ The airline's employment policy was not to hire any HIV-positive persons as cabin attendants. The Court held that this policy was not justified because some people living with HIV would not be able to work as cabin attendants. In highlighting the 'prevailing prejudice' against HIV-positive people, the Court held that unfair discrimination can never be justified by prejudice. 
Looking at the issue of involuntary sterilisation of HIV-positive women, the conduct does differentiate between people based on their HIV status. In determining whether such differentiation amounts to discrimination, although it is not a listed ground, the Court has clearly recognised HIV status as an analogous ground owing to its impairment of the human dignity of persons. Prejudice towards and stigmatisation of HIV-positive persons cannot justify unfair discrimination. The impact the conduct has on the victims renders this discrimination unfair. Victims in this regard are exposed to further stigmatisation socially and culturally. Their self-worth, autonomy and ultimately their human dignity, is violated by the disregard for their reproductive autonomy and the purpose of informed consent.

It would be difficult to justify this discrimination. Section 36 of the Constitution provides for the limitation of rights if it would be 'reasonable and justifiable in an open and democratic society based on human dignity, equality and freedom'. Section 36 provides that the following factors need to be considered when looking to justify the limitation of a right:

(a) the nature of the right;

(b) the importance of the purpose of the limitation;

(c) the nature and extent of the limitation;

(d) the relation between the limitation and its purpose; and

(e) less restrictive means to achieve the purpose.

Regarding the practice of involuntary sterilisation of HIV-positive women, these factors raise many concerns due to the misinformed purpose of the limitation, the extent of the limitation and the fact that there are less restrictive means of contraception and prevention of MTCT of HIV. Thus, this practice amounts to unfair discrimination that cannot be justified.

Additionally, as required by the doctrine of subsidiarity, PEPUDA would have to be utilised before relying on section 9 of the Constitution directly. Elaborating on the Constitutional provisions, section 14 of PEPUDA requires the context to be considered, a set of factors, and 'whether the discrimination reasonably and justifiably differentiates between persons according to objectively determinable criteria, intrinsic to the activity concerned.'The factors to be considered under section 14(3) include:

(a) whether the discrimination impairs or is likely to impair human dignity;

(b) the impact or likely impact of the discrimination on the complainant;

(c) the position of the complainant in society and whether he or she suffers from patterns of disadvantage or belongs to a group that suffers from such patterns of disadvantage;

(d) the nature and extent of the discrimination;

(e) whether the discrimination is systemic in nature;

(f) whether the discrimination has a legitimate purpose;

(g) whether and to what extent the discrimination achieves its purpose;

(h) whether there are less restrictive and less disadvantageous means to achieve the purpose;

(i) whether and to what extent the respondent has taken such steps as being reasonable in the circumstances to:

(ii) address the disadvantage that arises from or is related to one or more of the prohibited grounds; or

(iii) accommodate diversity.
In light of the context of the issue of involuntary sterilisation, these factors further impose a heavy burden on a respondent to justify the practice of involuntary sterilisation. Involuntary sterilisation certainly has an impact on human dignity, and has a complexity of effects on the victim, as illustrated in the contextual discussion above. The practice of involuntary sterilisation disproportionately affects HIV-positive black African women, who have been, and are still, subject to multiple forms of oppression and disadvantage in SA. PEPUDA requires that it be considered whether the discrimination is systemic in nature. Given SA's racially discriminatory past, the patriarchal society that persists, and the stigma around HIV, involuntary sterilisation in SA is necessarily systemic in nature. This is arguably so because the racial and gendered prejudices, coupled with the stigma of HIV, and even economic status, influence the healthcare workers performing this procedure. These prejudices have become entrenched in society. ${ }^{[3]}$ The latter factors in section 14(3) reflect those considered under section 36 of the Constitution.

Considering the systemic and institutionalised nature of the prejudice and stigmatisation that inform this unfair discrimination, Parker and Aggleton ${ }^{[15]}$ argue that power and domination play a role in the structural dimensions of discrimination. They hold that: ${ }^{[15,19]}$

'Focusing on the relations between culture, power and difference in the determination of stigmatisation encourages an understanding of HIV and AIDS-related stigmatisation and discrimination as part of the political economy of social exclusion present in the contemporary world.'

Considering such relationships provides a better understanding of such stigmatisation, and its consequences. It results in a further loss of power, and greater social exclusion. The prejudice acted on by healthcare providers, who are in a position of power, further undermines the woman's autonomy. Consequently, HIV is then conceptually linked to a woman's lack of child-bearing ability, and consequently her social and self-worth. A relationship between these two stigmatised statuses (HIV-positive and sterile) is created by the discriminatory practice without regarding a woman's reproductive autonomy, which should not be dependent on the opinion of others, albeit healthcare professionals. ${ }^{[1]}$

This practice also amounts to more than medical negligence or malpractice, owing to the systemic stigmatisation of HIV-positive persons. It is not an individual assessment, but a generalisation about HIV-positive persons and their reproductive decisions. The prejudice causing this discriminatory practice cannot justify it. Healthcare providers cannot rely on their ill-informed perceptions about and prejudices against HIV-positive women to justify the practice of involuntary sterilisation. Considering the discussion of informed consent above, perceptions and prejudices can also not justify the violation of this requirement to obtain informed consent.

\section{Conclusion}

The legal frameworks of consent and discrimination have been examined in the context of the involuntary sterilisation of HIVpositive women. From the contextual examination and the legal framework, it is evident that this practice occurs as a result of entrenched prejudice, a lack of understanding of medical advances in antiretrovirals, in the medical advances reducing the prevalence of HIV, and of the law regarding the obtaining of consent. This 
amalgamates into a practice of multidimensional discrimination, and results in subjecting the victims to further prejudice on the basis of their sterility. The stigmatisation and misconceptions regarding the reproductive autonomy of HIV-positive women overshadow the medical evidence and fundamental rights of these women.

Owing to the intersectional discrimination - individual, systemic and institutional - on various grounds - race, gender, HIV status, socioeconomic status - there is a need for a strong non-discriminatory approach to be taken in addressing this practice. As Patel argues:

'Once a court finds that the sterilisation is due to discriminatory practices, it can change the issue from one of a few bad incidents to one requiring structural reform. ${ }^{[3]}$

Such 'structural reform' includes addressing the broader systemic issues underlying the discrimination. A report by the Human Sciences Research Council released at the 2015 SA AIDS Conference on HIV Stigma found that out of 6719 HIV-positive women interviewed, 498 had been involuntarily sterilised. ${ }^{[16]}$ This shocking number of instances (which are still only the cases that are known) indicates that this is not merely an issue of individual discrimination and prejudice, but one with systemic and structural roots. There is therefore a need to address the issue through structural reform. Research is needed on how this can be done, perhaps through education and empowerment initiatives, but at the same time, litigation on this issue can add value in initiating reform initiatives.

This article has argued that the practice of involuntary sterilisation goes beyond the notions of medical malpractice or negligence, and actually amounts to a systemic problem of HIV stigmatisation, especially regarding reproductive health rights. To address such a systemic, seemingly engrained prejudice, radical and gendered redress needs to be available to the victims, and harsh consequences for those enabling this practice. Recourse and punishment is, however, not enough. Attention needs to be paid to educating women on their reproductive health rights and reproductive autonomy, so that they are empowered to explicitly refuse to consent, if they wish to do so. Educating women on their rights, as well as on consent and the consequences of sterilisation, can help break the cycle of stigmatisation, and allow for the enforcement of rights. Moreover, and perhaps more urgently, healthcare practitioners need to be thoroughly informed about the realities of HIV and the rights of the patient. This needs to be done in such a way that practitioners appreciate that their personal opinion cannot trump a woman's reproductive autonomy and the requirement for consent.
Understanding consent as a process is fundamental to this. The power imbalance makes the systemic problem difficult to address. Nonetheless, increased attention needs to be paid to rights education and the way in which consent is obtained. HIV-positive women's reproductive futures being subjected to the prejudices of ill-informed healthcare practitioners results in a situation where those in power (the healthcare practitioners) are playing God.

Acknowledgements. None.

Author contributions. Sole author.

Conflicts of interest. None.

Funding. None.

1. Strode A, Methembu S, Essack Z. 'She made a choice for me': 22 HIV-positive women's experiences of involuntary sterilisation in two South African provinces. Reprod Health Matters 2012;20(39 Suppl):S61-S69. https://doi.org/10.1016/ S0968-8080(12)39643-2

2. McLaughlin LC. The price of failure of informed consent law: Coercive sterilisation of HIV-positive women in South Africa. Law Ineq 2014;32(1):69-93.

3. Patel P. Forced sterilisation of women as discrimination. Public Health Rev 2017;38:15. https://doi.org/10.1186/s40985-017-0060-9

4. Mamad FAU. Forced sterilization of women living with HIV/AIDS in Africa. LLM thesis. Moka: University of Mauritius, 2009.

5. Badul CJ, Strode A. LM and Others v Government of the Republic of Namibia: The first Sub-Saharan African case dealing with coerced sterilisation of HIV-positive women - quo vadis? Afr Hum Rights Law Journal 2013;13(1):214-228.

6. Cooper D, Harries J, Myer L, Orner P, Bracken H, Zweigenthal V. 'Life is still going on': Reproductive intentions among HIV-positive women and men in South Africa. Soc Sci Med 2007;65(2):274-283. https://doi.org/10.1016/j. socscimed.2007.03.019

7. International Community of Women Living with HIV. Forced and coerced sterilization of women living with HIV, Issue Paper 3 http://www.iamicw.org/_ literature_144354/Issue_Paper_03_A4 (accessed 28 January 2018).

8. Government of the Republic of Namibia v LM and Others. 2014 NASC 19. Case $1603 / 2008$.

9. Barit A. The Doctrine of Informed Consent in South African Medical Law. LLB thesis. Pretoria: University of Pretoria 2017, https://repository.up.ac.za/bitstream/ handle/2263/60104/Barit_Doctrine_2017.pdf?sequence $=1$ (accessed 18 January 2018).

10. Castell v De Greef 1994 (4) All SA 63 (C).

11. Hall DR, van Niekerk AA. Reproductive autonomy: A case study. S Afr J Bioethics Law 2016;9(2):61-64. https://doi.org/10.7196/sajbl.2016.v9i2.496

12. World Health Organization. Eliminating Forced, Coercive and Otherwise Involuntary Sterilization. Geneva: WHO, 2014.

13. Harksen v Lane 1998 (1) SA 300 (CC).

14. Hoffman v South African Airways 2001 (1) SA 1 (CC).

15. Parker R, Aggleton P. HIV and AIDS-related stigma and discrimination: A conceptual framework and implications for action. Soc Sci Med 2003;57(1):13-24.

16. Human Sciences Research Council. Report: The People Living with HIV Stigma Index - South Africa 2014. Cape Town: HSRC, 2014.

Accepted 15 October 2018 